\title{
Synthesis of fructans by fructosyltransferase from the tuberous roots of Viguiera discolor (Asteraceae)
}

\section{N.M. Itaya, \\ R.C.L. Figueiredo-Ribeiro and M.S. Buckeridge}

\author{
Seção de Fisiologia e Bioquímica de Plantas, Instituto de Botânica, \\ Secretaria do M eio Ambiente do Estado de São Paulo, São Paulo, \\ $\mathrm{SP}$, Brasil
}

\section{Correspondence \\ R.C.L. Figueiredo-Ribeiro Seção de Fisiologia e Bioquímica de Plantas \\ Instituto de Botânica \\ Caixa Postal 4005 \\ 01061-970 São Paulo, SP \\ Brasil \\ Fax: + 55-11-5584-6300 \\ E-mail: ritarib@usp.br}

Research supported by FAPESP

Received July 22, 1998

Accepted January 26, 1999

\section{Abstract}

Sucrose:sucrose fructosyltransferase (SST) and fructan:fructan fructosyl-transferase (FFT) activities from crude extracts of tuberous roots of Viguiera discolor growing in a preserved area of cerrado were analyzed in 1995-1996. SST activity was characterized by the synthesis of 1-kestose from sucrose and FFT activity by the production of nystose from 1-kestose. The highest fructan-synthesizing activity was observed during early dormancy (autumn), when both (SST and FFT) activities were high. The increase in synthetic activity seemed to start during the fruiting phase in the summer, when SST activity was higher than in spring. During winter and at the beginning of sprouting, both activities declined. The in vitro synthesis of high molecular mass fructans from sucrose by enzymatic preparations from tuberous roots collected in summer showed that long incubations of up to $288 \mathrm{~h}$ produced consistently longer polymers which resembled those found in vivo with respect to chromatographic profiles.

\section{Introduction}

Fructans are polydisperse polysaccharides which constitute the major non-structural carbohydrate of many plant species, mainly in the economically important family Asteraceae (1). As a result, current interest in fructans is high because of their potential for technological applications in the food industry and for clinical and physiological renal research (2). Inulin, one of the best known fructans, has been shown to be suitable for measurement of glomerular filtration rate (GFR) (3). A comparison of inulin from Vernonia herbacea, a Brazilian Asteraceae species from the cerrado, and inulin from

\section{Key words}

- Inulin

- Fructosyltransferase

- Fructan biosynthesis

- Viguiera discolor

- Asteraceae
Dahlia sp, commercialized by Sigma Chemical Co., St. Louis, MO, USA, demonstrated that the former can substitute commercial inulin for the determination of GFR and can be used efficiently as a marker of tubular water reabsorption (4).

Underground organs presenting high amounts of fructans were found to be present in Asteraceae species from the Brazilian cerrado $(5,6)$ including the tuberous roots of Viguiera discolor that accumulate up to $80 \%$ of their dry mass as fructans of the inulin type. The mean molecular mass reaches 28 $\mathrm{kDa}$ (7), which is approximately five-fold higher than those currently found in the Asteraceae. However, the chromatographic 
profile of fructo-oligomers and the chain length of the polymers vary with the phenological cycle of this plant. The sprouting and flowering phases are characterized by the predominance of oligofructans up to degree of polymerization (DP) 4, whereas dormancy is associated with the presence of a continuous series of molecular masses between sucrose and polymers. These facts suggest that biosynthesis of fructans in $V$. discolor mainly occurs at the end of the growing period (autumn) in plants from the cerrado (1). Similar patterns have been described for plants from temperate climates that accumulate fructans, such as Helianthus tuberosus.

Concerning fructan biosynthesis, strong evidence suggests that these polymers are formed from sucrose by the concerted action of glycosyl transferases without the direct participation of sugar nucleotide intermediates. According to the proposed model (8), two enzymes are responsible for the synthesis of fructans. One of them is sucrose:sucrose fructosyl transferase (SST; EC 2.4.1.99), which irreversibly catalyzes the transfer of a fructosyl (F) between two sucrose molecules (GF) to form 1-kestose (GF-F) and glucose (G):

$$
\underset{\text { sucrose }}{\mathrm{GF}}+\mathrm{GF} \stackrel{\text { sucrose }}{\stackrel{\text { GFS }}{\longrightarrow}} \underset{1-\text { kestose }}{\mathrm{glucose}}
$$

The 1-kestose produced by SST can serve as an acceptor for single terminal fructosyl residue from other fructan chains (equal or higher than DP 3), the latter being the donors in the reactions catalyzed by fructan:fructan fructosyl transferase (FFT; EC 2.4.1.100) (8-10):

$$
\begin{aligned}
& \mathrm{GF}-(\mathrm{F})_{n}+\mathrm{GF}-(\mathrm{F})_{m} \stackrel{1-\mathrm{FFT}}{\longleftrightarrow} \mathrm{GF}-(\mathrm{F})_{n-1}+ \\
& \mathrm{GF}-(\mathrm{F})_{m+1} \text {, with } n>1, m>0
\end{aligned}
$$

The current model for fructan synthesis has been questioned especially with respect to grasses (11). However, de novo synthesis of fructans by a combination of 1-SST and
FFT purified from $H$. tuberosus tubers $(12,13)$ and from Cichorium intybus roots (14) starting from sucrose at physiologically relevant concentrations support this model, at least in the case of Asteraceae.

Cell-free synthesis of polyfructans in the presence of high sucrose concentrations has been demonstrated using enzymatic preparations from microorganisms and plants (15, and references therein) and also starting from the oligofructan nystose, using extracts from tuberous roots of $V$. discolor (16). These studies allowed the assessment of physiologically significant fructan biosynthesis by the selection of appropriate enzymatic systems.

In this paper we report the in vitro synthesis of high molecular mass fructans from sucrose by crude extracts of the tuberous roots of Viguiera discolor harvested in summer/autumn, when both SST and FFT activities were highest and the concentration of sucrose in the tissues was maximal.

\section{Material and Methods}

\section{Plant material}

Tuberous roots of Viguiera discolor Baker (Asteraceae) - (SP163681) were harvested in May 1995 and from March to December 1996 from plants growing naturally in a preserved area of cerrado near Moji-Guaçu, SP, Brazil (22 $\left.{ }^{\circ} 15-18^{\prime} \mathrm{S}, 47^{\circ} 8-12^{\prime} \mathrm{W}\right)$ at four phenological phases, as described previously (7). At least 10 adult plants bearing 15 to 20 tuberous roots/plant were collected at each phenological phase. The organs were transported inside plastic bags on dry ice and processed after at least $24 \mathrm{~h}$. These conditions were previously found not to affect enzyme activity (16). Tuberous roots of equal size (approximately $2.0 \mathrm{~cm}$ in diameter) were excised, thoroughly washed in tap water, peeled, cut into small pieces and utilized for soluble carbohydrate or enzyme extractions. 


\section{Preparation of enzyme extracts}

All procedures were carried out at $5^{\circ} \mathrm{C}$. Ten to $20 \mathrm{~g}$ (fresh weight) of tuberous roots were used for seasonal analysis and $270 \mathrm{~g}$ for purification purposes from plants in the fruiting phase. Immediately after excision, roots were homogenized for 3 min with a Waring blender in the same volume of ice-cold 50 $\mathrm{mM}$ Mcllvaine (citric acid - $\mathrm{Na}_{2} \mathrm{HPO}_{4}$ ) buffer, pH 5.5, containing $2 \mathrm{mM}$ EDTA, $2 \mathrm{mM}$ B-mercapto-ethanol, $0.05 \%$ sodium azide and $20 \mathrm{mM}$ pyridoxal hydrochoride. The slurry was filtered through two layers of nylon and centrifuged for $30 \mathrm{~min}$ at $31,000 \mathrm{~g}$.

To concentrate the enzyme extract (from plants in the fruiting phase only) ammonium sulfate was added to the supernatant (296 $\mathrm{ml})$ to $30 \%(\mathrm{w} / \mathrm{v})$ saturation, and proteins were allowed to precipitate for $4 \mathrm{~h}$. After centrifugation for $40 \mathrm{~min}$ at $10000 \mathrm{~g}$, the precipitate was discarded. The supernatant was brought to $65 \%(\mathrm{w} / \mathrm{v})$ saturation by further addition of ammonium sulfate. The precipitated proteins were collected as described above, re-dissolved in $8 \mathrm{ml}$ of $50 \mathrm{mM}$

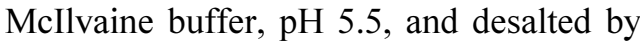
dialysis against $10 \mathrm{mM}$ Mcllvaine buffer, pH 5.5, for $24 \mathrm{~h}$, with 8 changes.

\section{Extraction and analysis of soluble carbohydrates}

Tuberous roots ( $1 \mathrm{~g}$ fresh weight) were killed instantly by chopping into boiling $80 \%$ $\mathrm{v} / \mathrm{v}$ ethanol and processed for soluble carbohydrate extraction according to a previously described method (17). Neutral soluble carbohydrates and products from enzyme reactions were analyzed by high performance anion exchange chromatography with pulsed amperometric detection (HPAEC/PAD) using a 4 x 250-mm CarboPac PA-1 column in a Dionex System Model DX 300 (18). Sugars were identified by co-chromatography with authentic standards. Purified samples of nystose and 1-kestose were kindly provid- ed by Dr. Norio Shiomi (Rakuno Gakuen University, Ebetsu, Hokkaido, Japan) and sucrose was obtained from Sigma. The apparent DP of the fructo-oligosaccharides was determined using the chromatographic mobility of fructans extracted from dormant tubers of $H$. tuberosus prepared according to Pollock (19). Alternatively, the polymers synthesized in vitro were analyzed on a CarboPac PA-100 column using a linear gradient of 25 $\mathrm{mM}$ to $500 \mathrm{mM}$ sodium acetate in $150 \mathrm{mM}$ sodium hydroxide at a flow rate of $1 \mathrm{~cm} / \mathrm{min}$ (20). Free and combined fructose were measured by a ketose-specific modification of the anthrone reaction (21), using inulin from $H$. tuberosus (Sigma) as standard. Oligosaccharides were analyzed qualitatively by thin layer chromatography (TLC) on silica gel plates developed as described by Cairns and Pollock (22). Ketoses were stained with ureaphosphoric acid (23) and identified by comparison with oligosaccharide standards of the inulin series prepared from tubers of $H$. tuberosus.

\section{Measurement of enzyme activity}

Samples of enzyme preparations $(100 \mu \mathrm{l})$ were mixed with an equal volume of 800 $\mathrm{mM}$ sucrose as substrate for SST activity and with $800 \mathrm{mM}$ 1-kestose as substrate for FFT activity in McIlvaine buffer, $\mathrm{pH}$ 5.4. The mixture was incubated at $30^{\circ} \mathrm{C}$ for $4 \mathrm{~h}$ (SST activity) and $6 \mathrm{~h}$ (FFT activity) as previously established (16). The reaction was stopped by injection of $2 \mu \mathrm{l}$ of the assay mixture directly into the HPAEC/PAD system. SST activity was calculated by direct measurement of total trisaccharide production in the reaction mixture whereas FFT activity was calculated by measurement of 1-kestose-dependent nystose production. Peak area was used for quantification (24).

The time course of fructan production was investigated using sucrose or 1-kestose $(800 \mathrm{mM})$ or nystose $(400 \mathrm{mM})$. The enzyme preparation was mixed $1: 1 \mathrm{v} / \mathrm{v}$ with the sub- 
Figure 1 - Sucrose:sucrose fructosyltransferase (SST) (black columns) and fructan:fructan fructosyltransferase (FFT) (gray columns) activities of extracts prepared from the tuberous roots of Viguiera discolor harvested during different phenological phases in the cerrado of MojiGuaçu (SP) from May 1995 to December 1996. LD = Late dormancy, ED = early dormancy, SP $=$ sprouting, $F R=$ fruiting.

Figure 2 - Products obtained from sucrose $(A)$, kestose $(B)$ and nystose (C). The extract prepared from the tuberous roots of Viguiera discolor at the fruiting phase was incubated with $400 \mathrm{mM}$ sucrose, $400 \mathrm{mM}$ 1kestose or $200 \mathrm{mM}$ nystose at $30^{\circ} \mathrm{C}$. The products glucose, fructose, sucrose, 1-kestose, nystose and $\mathrm{DP}>4$ were quantified. The consumption of the substrates used in each reaction mixture was not considered for the calculations, although they were detectable by HPLC.
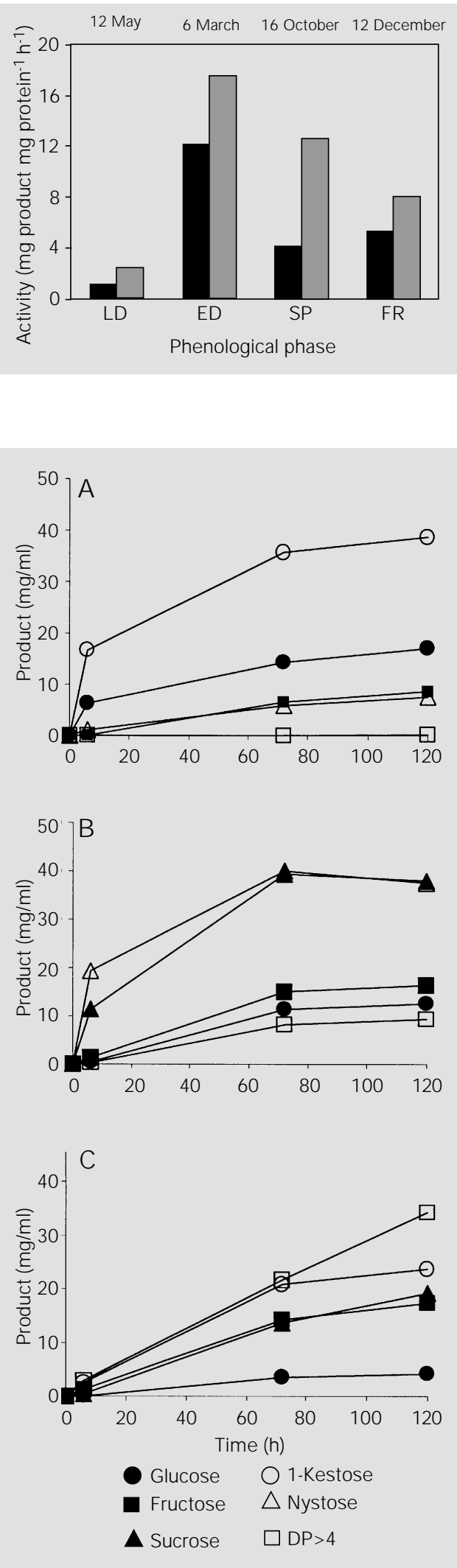

strate prepared in Mcllvaine buffer, $\mathrm{pH}$ 5.5, and incubated at $30^{\circ} \mathrm{C}$ for up to $288 \mathrm{~h}$. The assays were performed in sterile and sealed tubes and a layer of toluene was present throughout the incubation period. Samples of $2 \mu \mathrm{l}$ were collected at intervals over a 24$\mathrm{h}$ period and the reaction was stopped by injecting directly into the HPAEC/PAD system.

Protein concentrations in enzyme preparations were determined by the BioRad protein assay, which is based on the Bradford procedure (25). Bovine serum albumin was used as standard.

\section{Results and Discussion}

The metabolism of fructans among herbaceous plants from the Brazilian cerrado is largely affected by their phenological state, as observed from marked variations found in the content of fructans and patterns of molecular size distribution in several species $(1,7,18,26)$.

Analysis of fructans accumulated in the tuberous roots of Viguiera discolor at four phenological phases (7) showed that the lower content of the high molecular mass fraction was observed during the flowering phase, when larger amounts of low molecular mass saccharides were found. In those roots free fructose predominated throughout and a continuous series between sucrose and the high molecular mass fructan was found only during dormancy, indicating that fructans are synthesized and accumulated mainly during this period.

In order to understand the metabolism of fructans in plants, in vivo observations need to be correlated with in vitro measurements of relevant enzyme activities (27). In the present study we followed the fructan synthesizing activities throughout the phenological cycle of $V$. discolor growing naturally in the cerrado. As shown in Figure 1, SST activity clearly increased after the reproductive phase, being higher at early dor- 
mancy. FFT activity increased over the same period although the decrease in activity after dormancy was less pronounced, mainly if based on fresh mass. FFT activity was higher than SST activity and nearly constant over the phenological cycle of $V$. discolor, as also reported for a number of plant species that store fructans. During winter and at the beginning of the sprouting phase (July-August) both SST and FFT activities practically disappeared (data not shown).

Figure 2 shows the quantitative changes in mono- (glucose and fructose), oligo- (sucrose and 1-kestose) and higher molecular mass oligosaccharides during in vitro incubation with sucrose (Figure 2A), 1-kestose (Figure 2B) and nystose (Figure 2C). When sucrose is the substrate (Figure 2A), fructose is transferred to sucrose, forming 1-kestose. This characterized the presence of SST activity in the extracts. Likewise, the enzymatic system transferred fructose between 1-kestose molecules, probably by the action of FFT (Figure 2B). The fructan-synthesizing activity was not as effective when nystose was the substrate, showing a much lower initial velocity of production of higher molecular mass fructans (Figure 2C). However, a much larger proportion of fructans (DP $>4)$ was found after $120 \mathrm{~h}$ of incubation with 1kestose. This observation was confirmed even after $288 \mathrm{~h}$ of incubation (Figure 3 ). These results suggest that different fructose-transferring mechanisms might operate when different substrates are used. In other words, the predominance of sucrose, 1-kestose or nystose in vivo is likely to determine the average molecular mass of the fructan found during the next phenological phase.

According to the current model proposed for fructan metabolism in Asteraceae (8) FFT plays a key role during both fructan synthesis and breakdown. Indeed Figures 2 and 3 show high proportions of free fructose in the reaction mixture indicating that FFT could also be responsible for fructan mobilization in this plant, transferring fructose to

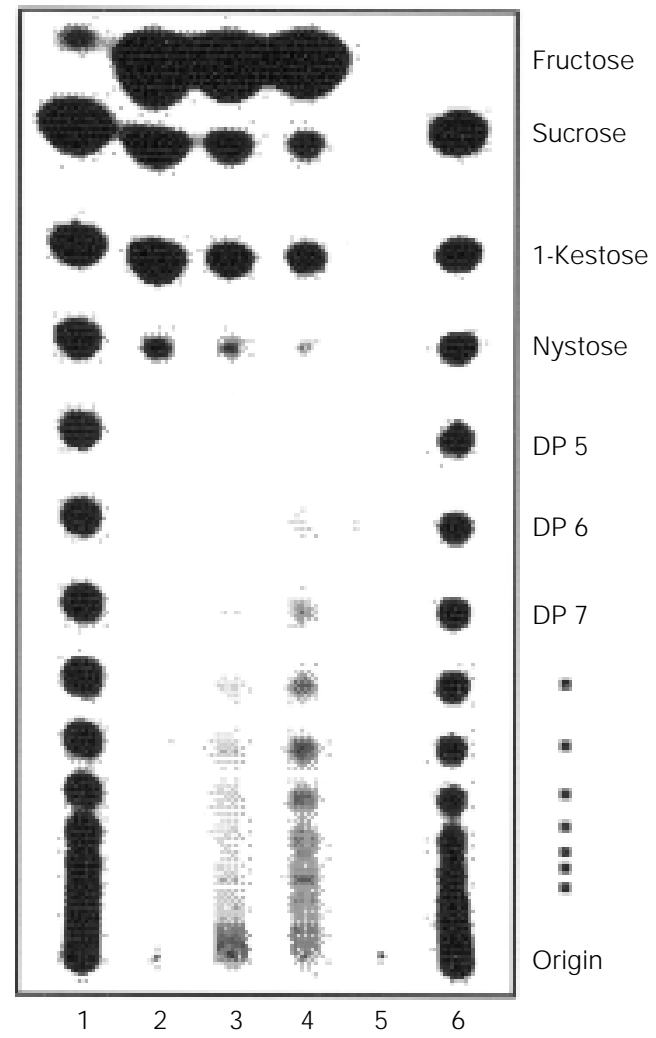

Figure 3 - TLC of fructo-oligosaccharides produced after $288 \mathrm{~h}$ incubation of an extract of the tuberous roots of Viguiera discolor with $400 \mathrm{mM}$ sucrose (2), $400 \mathrm{mM}$ 1-kestose (3) and 200 $\mathrm{mM}$ nystose (4). Fructo-oligosaccharides from tubers of Helianthus tuberosus (lanes 1 and 6) and an enzymatic extract from V. discolor without substrate (lane 5) were used as standards. Each lane contains approximately $50 \mu \mathrm{g}$ fructose equivalents. DP $=$ Degree of polymerization. water (28). This was observed after long incubations with nystose as substrate (Figure 3). As observed in chicory roots (14), the decrease of SST can enhance the competitive inhibition by sucrose as an acceptor for FFT. Then this enzyme might start to depolymerize larger fructans to smaller ones by fructosyl transfer to sucrose, exhibiting a role in the catabolism of fructans.

Analysis by HPAEC/PAD of the reaction products after long periods of incubation of sucrose with enzymatic preparations from plants collected at the fruiting phase showed that a complete series of fructans can be synthesized in vitro (Figures 4 and 5) and that they are similar to those found in vivo in plants naturally growing in the cerrado. It is important to note that the data shown in Figures 4 and 5 were obtained after injection of different concentrations of polysaccharides and analyzed by two different chromatographic systems (i.e., a Carbopak PA1 column for oligosaccharide analysis and a 
Figure 4 - HPAEC/PAD analysis of fructans on a CarboPack PA-1 column produced after incubation of an enzyme preparation from the tuberous roots of Viguiera discolor collected at the fruiting phase with $400 \mathrm{mM}$ sucrose. Incubation was performed for $288 \mathrm{~h}$ at $30^{\circ} \mathrm{C}$ and products (in vitro) were compared with soluble neutral carbohydrates (SNC) extracted from the same tissue (in vivo). The enzyme preparation is equivalent to 325 $\mu \mathrm{g}$ protein/ml and SNC is equivalent to $1 \mathrm{mg}$ fresh mass of tuberous roots. Control represents 0 min incubation. $\mathrm{G}=$ Glucose, $\mathrm{F}=$ fructose, $S=$ sucrose, $1 \mathrm{~K}=1$ kestose, $\mathrm{N}=$ nystose. Numbers indicate the estimated degree of polymerization.

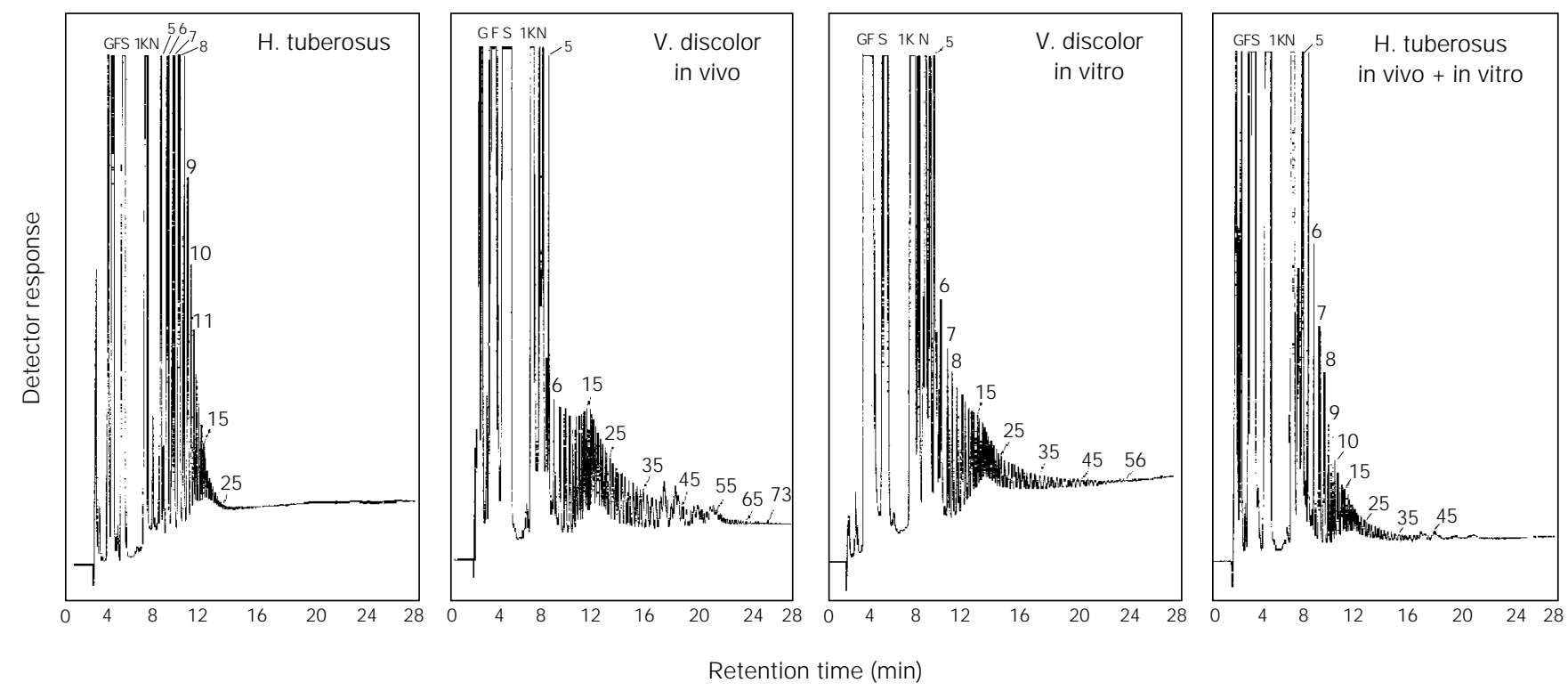

Figure 5 - HPAEC/PAD analysis of fructans on a CarboPack PA- 100 column produced after incubation of an enzyme preparation from the tuberous roots of Viguiera discolor collected at the fruiting phase with $400 \mathrm{mM}$ sucrose. Incubation was performed for $288 \mathrm{~h}$ at $30^{\circ} \mathrm{C}$ and products (in vitro) were compared with fructans extracted from the same tissue (in vivo) and from tubers of $\mathrm{H}$. tuberosus. Sample concentration was $4 \mathrm{mg} / \mathrm{ml}$ fructose equivalents. $\mathrm{G}=$ Glucose, $\mathrm{F}=$ fructose, $\mathrm{S}=$ sucrose, $\mathrm{IK}=1$-kestose, $\mathrm{N}=$ nystose. Numbers indicate the estimated degree of polymerization. 


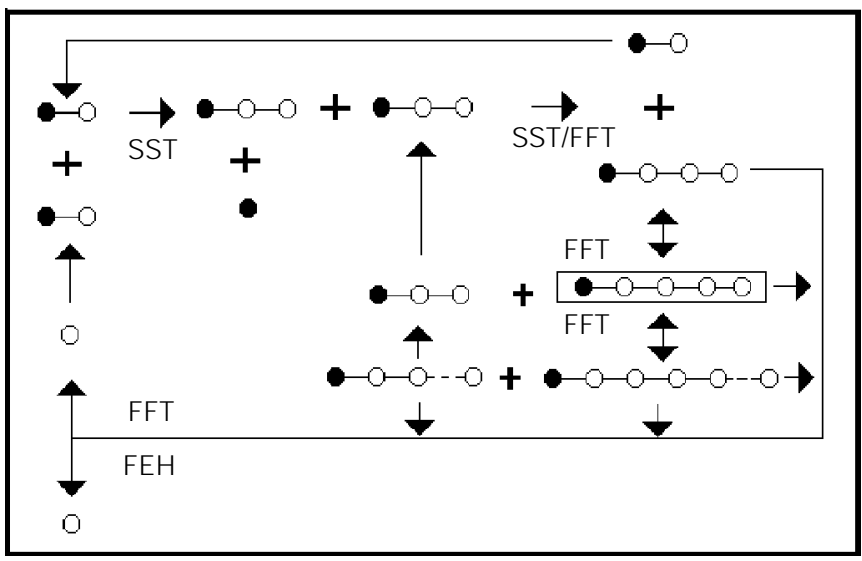

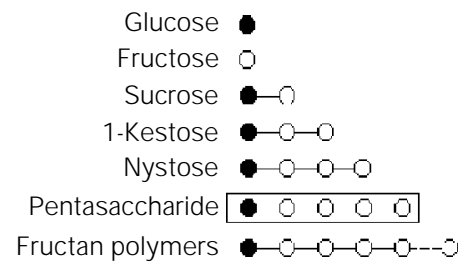

Carbopak PA100 column for polysaccharide analysis).

Although the retention times of fructans from tuberous roots of $V$. discolor are similar to those from the inulin series present in tubers of Helianthus tuberosus, suggesting that Viguiera discolor contains a $\beta, 2-1$ fructan series, the abundance of individual components is different, as previously indicated $(7,16)$. Instead of a complete homologous series with proportional amounts of all members, a predominance of components around DP 15 was found in in vivo and in vitro synthesized fructans in $V$. discolor (Figure 5). However, the oligosaccharides with DP from 5 to 15 synthesized in vitro were present in higher proportions compared to those synthesized in vivo.

How the synthesis of fructans differs between Helianthus and Viguiera is not clear, but the latter seems to be able to use nystose to produce polysaccharides in a different fashion. On the basis of the enzyme activi- ties and the substrates detected in vitro and in vivo in tuberous roots of Viguiera discolor and the current information on fructan biosynthesis, a tentative model for the reactions of inter-conversions between sucrose and fructan oligo- and polysaccharides within the incubation media of Viguiera discolor is proposed (Figure 6). Our results suggest that FFT from $V$. discolor, differently from other Asteraceae studied (14), has higher affinity for nystose and mainly for the pentasaccharide, since both are usually present in much smaller proportions among the other components of the inulin series in the incubation mixture. It is important to note that the elucidation of this mechanism will be of biotechnological value since high molecular mass fructans of the inulin series, which are of commercial value, can be easily produced in vitro with crude extracts from underground reserve organs of Viguiera discolor.
Figure 6 - Reaction scheme for reactions between sucrose and oligo- and polysaccharides within incubation media of the fructan synthesizing system of Viguiera discolor. Pentasaccharide is shown in a box because it is thought to be the principal substrate for FFT activity. SST = Sucrose:sucrose fructosyltransferase, FFT = fructan:fructan fructosyltransferase, FEH = fructan hydrolase.

\section{References}

1. Figueiredo-Ribeiro RCL, Isejima EM, DiasTagliacozzo GM, Carvalho MAM \& Dietrich SMC (1991). The physiological significance of fructan accumulation in Asteraceae from the Cerrado. Ciência e Cultura, 43: 443-446.

2. Fuchs A (1993). Production and utilization of inulin. Part II. Utilization of inulin. In: Suzuki M \& Chatterton NJ (Editors), Sci- ence and Tecnology of Fructans. CRC Press, Boca Raton, FL, 319-352.

3. Brenner BM, Dworkin LD \& Ichikawa I (1986). Glomerular ultrafiltration. In: Brenner MD, Floyd C \& Rector MD (Editors), The Kidney. WB Saunders Company, Philadelphia, 124-144.

4. Dias-Tagliacozzo GM, Dietrich SMC \& Mello-Aires M (1996). Measurement of glomerular filtration rate using inulin prepared from Vernonia herbacea, a Brazilian native species. Brazilian J ournal of Medical and Biological Research, 29: 13931396.

5. Figueiredo-Ribeiro RCL, Dietrich $S M C$, Chu EP, Machado de Carvalho MA, Vieira CCJ \& Graziano TT (1986). Reserve carbohydrate in underground organs of native 
Brazilian plants. Revista Brasileira de Botânica, 9: 159-166.

6. Tertuliano MF \& Figueiredo-Ribeiro RCL (1993). Distribution of fructose polymers in herbaceus species of Asteraceae from the cerrado. New Phytologist, 123: 741749.

7. Isejima EM \& Figueiredo-Ribeiro RCL (1993). Dynamics of fructans in tuberous roots of Viguiera discolor Baker (Asteraceae) as influenced by phenology. Plant Cell Physiology, 34: 723-727.

8. Edelman J \& J efford TG (1968). The mechanism of fructosan metabolism in higher plants as exemplified in Helianthus tuberosus. New Phytologist, 67: 517-531.

9. Lüscher $M$, Frehner $M \&$ Nosberger J (1993). Purification and characterization of fructan:fructan fructosyl transferase from J erusalem artichoke (Helianthus tuberosus L.). New Phytologist, 123: 717-724.

10. Koops AJ \& J onker HH (1994). Purification and characterization of the enzymes of fructan biosynthesis in tubers of Helianthus tuberosus Colombia. I. Fructan: fructan fructosyltransferase. J ournal of Experimental Botany, 45: 1623-1631.

11. Caims AJ (1993). Evidence for the novo synthesis of fructan by enzymes from higher plants: a reappraisal of the SST/ FFT model. New Phytologist, 123: 15-24.

12. Lüscher $\mathrm{M}$, Erdin $\mathrm{C}$, Sprenger $\mathrm{N}$, Hochstrasser U, Boller T \& Wiemkem A (1996). Inulin synthesis by a combination of purified fructosyltransferase from tubers of Helianthus tuberosus. FEBS Letters, 385: 39-42.

13. Koops AJ \& J onker HH (1996). Purification and characterization of the enzymes of fructan biosynthesis in tubers of Helianthus tuberosus Colombia. II. Purifica- tion of sucrose:sucrose 1-fructosyltransferase and reconstitution of fructan synthesis in vitro with purified sucrose:sucrose 1-fructosyltransferase and fructan: fructan 1-fructosyltransferase. Plant Physiology, 110: 1167-1175.

14. Van den Ende W \& Van Laere A (1996). De-novo synthesis of fructans from sucrose in vitro by a combination of two purified enzymes (sucrose:sucrose 1fructosyl transferase and fructan:fructan 1-fructosyl transferase) from chicory roots (Cichorium intybus L.). Planta, 200: 335342.

15. Penson SP \& Cairns AJ (1994). Fructan biosynthesis in excised leaves of wheat (Triticum aestivum L.): a comparison of de novo synthesis in vivo and in vitro. New Phytologist, 128: 395-402.

16. Itaya NM, Buckeridge MS \& FigueiredoRibeiro RCL (1997). Biosynthesis in vitro of high molecular mass fructan by cellfree extracts from tuberous roots of Viguiera discolor Baker (Asteraceae). New Phytologist, 136: 53-60.

17. Pollock CJ \& Jones T (1979). Seasonal patterns of fructan metabolism in forage grasses. New Phytologist, 83: 9-5.

18. Vieira CCJ \& Figueiredo-Ribeiro RCL (1993). Fructose-containing carbohydrates in tuberous root of Gomphrena macrocephala St.-Hil. (Amaranthaceae) at different phenological phases. Plant Cell Environment, 16: 919-928.

19. Pollock CJ (1982). Oligosaccharide intermediates of fructan synthesis in Lolium temulentum. Phytochemistry, 21: 24612465.

20. Shiomi N (1993). Structure of fructopolysaccharide (asparagosin) from roots of asparagus (Asparagus officinalis L.).
New Phytologist, 123: 263-270.

21. J ermyn MA (1956). A new method for the determination of ketohexoses in presence of aldohexoses. Nature, 177: 38-39.

22. Cairns AJ \& Pollock CJ (1988). Fructan biosynthesis in excised leaves of Lolium temulentum L. I. Chromatographic characterization of oligofructan and their labelling patterns following ${ }^{14} \mathrm{CO}_{2}$ feeding. New Phytologist, 109: 399-405.

23. Wise CS, Dimler RJ , Davis HA \& Rist CE (1955). Determination of easily hydrolyzable fructose units in dextran preparation. Analytical Chemistry, 27: 33-36.

24. Timmermans JW, Van Leeuwen MB, Tournois $H$, de Wit $D \&$ Vliegenthart J FG (1994). Quantitative analysis of the molecular weight distribution of inulin by means of anion exchange HPLC with pulsed amperometric detection. J ournal of Carbohydrate Chemistry, 13: 881-888.

25. Bradford MM (1976). A rapid and sensitive method for the quantitation of microgram quantities of protein utilizing the principle of protein-dye binding. Analytical Biochemistry, 72: 248-254.

26. Carvalho MAM \& Dietrich SMC (1993). Variation in fructan contents in the underground organs of Vemonia herbacea (Vell.) Rusby at different phenological phases. New Phytologist, 123: 735-740.

27. Van den Ende W \& Van Laere A (1996). Fructan synthesizing and degrading activities in chicory roots (Cichorium intybus L.) during field-growth, storage and forcing. J ournal of Plant Physiology, 149: 43-50.

28. Lüscher M \& Nelson CJ (1995). Fructosyltransferase activities in the leaf growth zone of Tall Fescue. Plant Physiology, 107: 1419-1425. 